\title{
In vitro antimicrobial susceptibility testing of human Brucella melitensis isolates from Ulanqab of Inner Mongolia, China
}

Zhi-guo Liu' ${ }^{1,2,4}$, Dong-dong Di ${ }^{3}$, Miao Wang ${ }^{2}$, Ri-hong Liu, Hong-yan Zhao ${ }^{4}$, Dong-ri Piao ${ }^{4}$, Zhong-zhi Zhao ${ }^{4}$, Yong-qing Hao', Ya-nan Du', Hai Jiang ${ }^{4^{*}}$, Bu-yun Cui ${ }^{4^{*}}$ and Xian-zhu Xia' ${ }^{1,5^{*}}$

\begin{abstract}
Background: Brucellosis is an endemic disease in the Inner Mongolia Autonomous Region of China and Ulanqab exhibits the highest prevalence of brucellosis in this region. Due to the complex nature of Brucellosis, a cure for this disease has proven to be elusive. Furthermore, the reduced susceptibility of Brucella spp. to antimicrobial agents has been reported as a potential cause of therapeutic failure. However, detailed in vitro antimicrobial susceptibility patterns pertaining to Brucella isolates from this region have not yet been published. The aim of this study was to evaluate the antibiotic susceptibility profile of Brucella melitensis clinical isolates from Ulanqab, Inner Mongolia, China.

Methods: A total of 85 B. melitesis isolates were obtained from humans in Ulanqab of Inner Mongolia, China; the antimicrobial susceptibility of 85 clinical isolates to nine antibiotics was assessed using the E-test method according to the CLSI (Clinical and Laboratory Standards Institute) guidelines.

Results: All of the tested isolates were susceptible to minocycline, sparfloxacin, doxycycline, tetracycline, ciprofloxacin, gentamicin and levofloxacin. Resistance to rifampin and cotrimoxazole was observed in 1.0\% (1/85) and $7.0 \%(6 / 85)$ of the isolates, respectively. However, rpoB gene mutations were not observed in single isolates exhibiting resistance to rifampin.

Conclusions: We observed that B. melitensis isolates are susceptible to the majority of the tested antibiotics. Furthermore, minocycline and sparfloxacin exhibited extremely high bactericidal effects in relation to the B. melitensis isolates. The sensitivity of commonly used drugs for the treatment of brucellosis should be regularly monitored. To the best of our knowledge, this is the first report of rifampin and cotrimoxazole resistant isolates of $B$. melitensis in China. In summary, based on the findings from this study, we suggest that antibiotic administration and use should be rationalized to prevent future drug resistance.
\end{abstract}

Keywords: Brucella melitensis, brucellosis, Antimicrobial susceptibility, Ulanqab, Inner Mongolia

\footnotetext{
*Correspondence: jianghai@icdc.cn; cuibuyun@icdc.cn; xiaxzh@cae.cn

${ }^{4}$ State Key Laboratory for Infectious Disease Prevention and Control, National Institute for Communicable Disease Control and Prevention/Collaborative Innovation Center for Diagnosis and Treatment of Infectious Disease, Chinese Center for Disease Control and Prevention, 155 Changbai Road, Changping, Beijing 102206, People's Republic of China

${ }^{1}$ College of Veterinary Medical Inner Mongolia Agriculture University, Hohhot 010018, China

Full list of author information is available at the end of the article
}

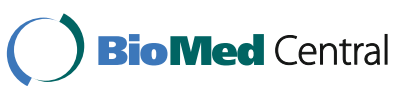

(c) The Author(s). 2018 Open Access This article is distributed under the terms of the Creative Commons Attribution 4.0 International License (http://creativecommons.org/licenses/by/4.0/), which permits unrestricted use, distribution, and reproduction in any medium, provided you give appropriate credit to the original author(s) and the source, provide a link to the Creative Commons license, and indicate if changes were made. The Creative Commons Public Domain Dedication waiver (http://creativecommons.org/publicdomain/zero/1.0/) applies to the data made available in this article, unless otherwise stated. 


\section{Background}

Brucellosis is a zoonotic disease that can cause severe morbidity in humans. This disease also results in multifarious medical challenges globally, especially in developing regions [1]. The genus Brucella encompasses intracellular bacterial pathogens that infect host macrophage cells [2]. Thus, associated treatment regimens are protracted and require macrophage penetration to facilitate effective treatment [3]. Therefore, only a limited number of antibiotics are effective against the causative microorganisms.

Inner Mongolia has experienced a dramatic history of brucellosis, and incidences of human brucellosis have risen rapidly since 2010 [4]. Ulanqab exhibits the highest prevalence of brucellosis in Inner Mongolia. Between 2011 and 2015, the average annual incidence of brucellosis was 57/100,000. In this study, almost all of the 85 patients analyzed had a history of exposure to sheep, and contact with infected domestic animals (sheep) was the most likely source of infection. Furthermore, we speculate that contaminated animal produce (e.g., undercooked meat and unpasteurized milk) is also as an important source of infection. However, misdiagnosis and mistreatment are widespread due to the fact that brucellosis patients typically lack obvious signs and symptoms of infection [5, 6]. In the majority of cases, therapeutic failure is caused by inadequate therapeutic regimens. Although resistant strains are rarely caused by therapy failure, resistance to commonly used antimicrobial agents may lead to treatment inhibition. Consequently, a human brucellosis diagnostic and treatment project was initiated by the Department of Health of the Inner Mongolia autonomous region in 2011. This program aimed to normalize brucellosis diagnosis and treatment, and improve the regimens used to treat brucellosis, thereby ameliorating problems relating to brucellosis chronicity. The project detailed which antibiotics should be chosen to treat the bacterial infective agents that cause brucellosis. This project also published recommendations regarding which antibiotic combinations should be utilized for infections. Unfortunately, detailed in vitro antimicrobial susceptibility patterns pertaining to Brucella isolates from this region have not yet been published. Furthermore, some studies have also shown that drug regimen recommendations published by WHO are not always implemented in clinical practice and relapses due to inadequate therapy occurs in $5-10 \%$ of patients [7]. Consequently, sporadic cases of human Brucella isolates with antibiotic resistance [8,9] and human Brucella isolates that are resistant to rifampin and cotrimoxazole have been reported $[10,11]$. Thus, the main objective of this study was to determine the antimicrobial susceptibility profile of human Brucella isolates. It is hoped that this information will provide a platform that will help to elucidate the most optimal regimens for brucellosis treatment, thereby facilitating the discovery of more effective therapeutic drug treatment strategies for brucellosis treatment.

\section{Methods \\ Bacterial isolates}

A total of 85 Brucella isolates obtained from patient blood samples $(n=85)$ were collected between March 2011 and September 2015 in Ulanqab, Inner Mongolia. The identification of isolates was based on standard procedures [12], and included analysis of colony morphology, Gram stain reaction, $\mathrm{CO}_{2}$ requirements, $\mathrm{H}_{2} \mathrm{~S}$ production, inhibition of growth by basic Fuchsin and Thionin, agglutination with monospecific antisera and phage lysis testing. Species-level identification was undertaken using B. abortus, B. melitensis, B. ovis, B. suis PCR (AMOS-PCR) [13]. All cultures were processed in a Biological Safety Laboratory III.

\section{Antimicrobial susceptibility testing}

In vitro evaluations of antibiotic efficacy against $B$. melitensis were based on the Minimal Inhibitory Concentration (MIC) values. The MIC's $\left(\mathrm{MIC}_{50}\right.$ and $\left.\mathrm{MIC}_{90}\right)$ of rifampin, doxycycline, gentamicin, tetracycline, ciprofloxacin, levofloxacin, minocycline, sparfloxacin and cotrimoxazole to Brucella melitensis were determined using the E-test strip method (E-test strips, Wenzhou kont biology and technology, Ltd., China) according to the CLSI guidelines. The plates were incubated in ambient air at $35{ }^{\circ} \mathrm{C}$ and evaluated after $48 \mathrm{~h}$. MIC breakpoints of levofloxacin, tetracycline, doxycycline and cotrimoxazole were used as recommended by CLSI [14]. Because MIC breakpoints for Brucella against rifampin, ciprofloxacin and other antibiotics have not yet been established, guidelines for slow-growing bacteria ( $H$. influenzae) were used as an alternative [15]. The MIC was interpreted as the value at which the inhibition zone intercepted the scale on the E-test strip. $\mathrm{MIC}_{50}$ and $\mathrm{MIC}_{90}$ levels were defined as the lowest concentration of the antibiotic at which $50 \%$ and $90 \%$ of the isolates were inhibited, respectively. The reference strains, B. melitensis $16 \mathrm{M}$ and $H$. influenza ATCC 10211I, were used as quality control strains.

\section{PCR assay of the rpoB gene}

Two hot spots in the $r p o B$ (RNA polymerase, beta subunit) gene along with the whole $r p o B$ gene were amplified and sequenced for isolates $(n=3)$ that showed an elevated MIC value to rifampin ( $\geq 2 \mu \mathrm{g} / \mathrm{mL}$ ), as described previously [16, 17]. Sequence and data analysis were conducted as previously described [16]. 


\section{Results}

The MIC range, $\mathrm{MIC}_{50}$ and $\mathrm{MIC}_{90}$ values of Brucella melitensis are shown in Table 1. All of the tested isolates were susceptible to minocycline $\left(\mathrm{MIC}_{90}, 0.032 \mu \mathrm{g} / \mathrm{mL}\right.$ ) and sparfloxacin $\left(\mathrm{MIC}_{90}, 0.032 \mu \mathrm{g} / \mathrm{mL}\right)$. In addition, doxycycline $\left(\mathrm{MIC}_{90}, 0.25 \mu \mathrm{g} / \mathrm{mL}\right)$, gentamicin $\left(\mathrm{MIC}_{90}\right.$, $1 \mu \mathrm{g} / \mathrm{mL}$ ), tetracycline $\left(\mathrm{MIC}_{90}, 0.5 \mu \mathrm{g} / \mathrm{mL}\right)$, ciprofloxacin $\left(\mathrm{MIC}_{90}, 0.5 \mu \mathrm{g} / \mathrm{mL}\right)$ and levofloxacin $\left(\mathrm{MIC}_{90}, 0.5 \mu \mathrm{g} / \mathrm{mL}\right)$ showed $100 \%$ susceptibility when MIC breakpoint criteria for $H$. influenzae [14] were used. Rifampin MIC values ranged from 0.5 to $2 \mu \mathrm{g} / \mathrm{mL}$ and when compared with MIC breakpoint criteria for $H$. influenzae [14], resistance (MIC $\geq 2 \mathrm{mg} / \mathrm{L}$ ) was demonstrated in $1.0 \%$ $(1 / 85)$ of the analyzed strains. Fifty-nine strains were susceptible to rifampin, twenty-five strains exhibited intermediate-resistance to rifampin and one strain was resistant to rifampin. After sequencing of the rpo $B$ gene, no mutations were observed. The cotrimoxazole MIC values ranged from 0.032 to $2 \mu \mathrm{g} / \mathrm{mL}$ $\left(\mathrm{MIC}_{90}, 1.0 \mu \mathrm{g} / \mathrm{mL}\right)$. Six strains exhibited resistance to cotrimoxazole. No association between biovar type and the susceptibility profile of the tested $B$. melitensis strains was observed. The MIC values $(\mu \mathrm{g} / \mathrm{mL})$ of 85 B. melitensis strains are shown in Table 2.

\section{Discussion}

In the present study, we investigated the in vitro susceptibility of 85 B. melitensis strains isolated from humans in Ulanqab (where human brucellosis is endemic) to a variety of antibiotics that are commonly used in brucellosis treatment including rifampin, doxycycline, levofloxacin, tetracycline. In addition, two new antibiotics, sparfloxacin and minocycline, were also evaluated (Table 1). All of the isolates were susceptible to all of the analyzed antibiotics apart from rifampin and cotrimoxazole. A total of $1 \%(1 / 85)$ of the analyzed strains were resistant to rifampin and $7.0 \%(6 / 85)$ of the isolates were resistant to cotrimoxazole. These results are similar to those previously reported. Abdel Maksoud et al. reported that $64 \%$ of Brucella isolates from Egypt were resistant to rifampin [18]. Similarly, Lopez-Merino et al. reported that rifampin was less effective than other antibiotics against Brucella strains, and cotrimoxazole showed the poorest activity with an $\mathrm{MIC}_{90}$ of $8.0 \mathrm{mg} / \mathrm{mL}$ [19]. Furthermore, Ilhan et al. also reported a resistance rate of 9.7\% to rifampin for $B$. melitensis and the highest resistance rate (46.3\%) was observed for cotrimoxazole [20]. China is the world's most populous country and tens of thousands of tons of antibiotics are used annually. Recent research has revealed that the total usage of antibiotics in China has reached 162,000 tons; this is almost equal to half of the total global usage of antibiotics. In 2013, approximately 7890,6950 , and 22,500 tons of sulfonamides, tetracyclines, and quinolones were used in China, respectively. The amount of rifampin used in 2013 remains unknown; however, it is not likely to be less than the any of the afore-mentioned antibiotics.

Therefore, in order to better understand the use of antibiotics in China this current study assessed a total of nine antibiotics; these antibiotics are the most commonly used drugs in the treatment of brucellosis and should be regularly monitored in relation to drug susceptibility.

Rifampin belongs to the rifamycin group of antibiotics and elicits its bactericidal effects by blocking the synthesis of bacterial RNA and protein [21]. In the present study, 96.5\% (82/85) of Brucella strains with MIC $\leq$ $1 \mu \mathrm{g} / \mathrm{mL}$ for rifampin were considered susceptible according to the CLSI breakpoints for slow-growing bacteria. Two Brucella strains exhibited higher MIC's of rifampin $(\geq 2 \mu \mathrm{g} / \mathrm{mL})$ and one strain was resistant to rifampin. Interestingly, higher MIC's of rifampin have been reported in relation to a significant proportion of strains in Egypt (64\%) [18], Malaysia (70\%) [22] and Brazil (36.73\%) [10]. Furthermore, some of the strains that were shown to be resistant to rifampin were also observed in previous studies that were performed in Turkey (9.7\%) [20] and Brazil (2.04\%). However, the

Table $1 \mathrm{MIC}$ range and $\mathrm{MIC}_{50}$ and $\mathrm{MIC}_{90}$ values of nine antimicrobial agents

\begin{tabular}{|c|c|c|c|c|c|c|c|}
\hline Antibiotic & Range $(\mu \mathrm{g} / \mathrm{mL})$ & $\mathrm{MIC}_{50}(\mu \mathrm{g} / \mathrm{mL})$ & $\mathrm{MIC}_{90}(\mu \mathrm{g} / \mathrm{mL})$ & (S) & (I) & (R) & $\begin{array}{l}\text { Breakpoint for } \\
\text { Susceptibility }(\mu \mathrm{g} / \mathrm{mL})\end{array}$ \\
\hline Minocycline & 0.032 & 0.032 & 0.032 & 85 & - & - & $\leq 0.5^{a}$ \\
\hline Sparfloxacin & 0.032 & 0.032 & 0.032 & 85 & - & - & $\leq 0.5^{\mathrm{a}}$ \\
\hline Doxycycline & $0.032-0.25$ & 0.125 & 0.25 & 85 & - & - & $\leq 1$ \\
\hline Tetracycline & $0.064-1.0$ & 0.25 & 0.5 & 85 & - & - & $\leq 1$ \\
\hline Ciprofloxacin & $0.125-1.0$ & 0.5 & 0.5 & 85 & - & - & $\leq 1^{\mathrm{a}}$ \\
\hline Levofloxacin & $0.125-1.0$ & 0.5 & 0.5 & 85 & - & - & $\leq 1$ \\
\hline Gentamicin & $0.25-1.0$ & 0.5 & 1.0 & 85 & - & - & $\leq 4^{\mathrm{a}}$ \\
\hline Rifampin & $0.5-2.0$ & 0.5 & 1.0 & 59 & 25 & 1 & $\leq 2^{\mathrm{a}}$ \\
\hline Cotrimoxazole & $0.032-2.0$ & 0.5 & 1.0 & 79 & - & 6 & $\leq 2 / 38$ \\
\hline
\end{tabular}

${ }^{a}$ CLSI breakpoints for slow-growing bacteria (Haemophilus spp.) 
Table 2 The MIC values $(\mu \mathrm{g} / \mathrm{mL})$ for Brucella melitensis strains (n: 85)

\begin{tabular}{lcccccccc}
\hline Antibiotics & \multicolumn{7}{c}{ MIC results $(\mathrm{\mu g} / \mathrm{mL})$} \\
\cline { 2 - 9 } & 0.032 & 0.064 & 0.125 & 0.25 & 0.5 & 1 & 2 & $\mathrm{R}$ \\
\hline Minocycline & 85 & & & & & & & \\
Sparfloxacin & 85 & & & & & & & \\
Doxycycline & 3 & 17 & 24 & 41 & & & & \\
Tetracycline & & 15 & 21 & 16 & 30 & 3 & & \\
Ciprofloxacin & & & 2 & 34 & 47 & 2 & & \\
Levofloxacin & & & 5 & 24 & 52 & 4 & & \\
Gentamicin & & & & 15 & 55 & 15 & & \\
Rifampin & & & & & 59 & 23 & 2 & 1 \\
Cotrimoxazole & 7 & 16 & 11 & 10 & 12 & 21 & 2 & 6 \\
\hline
\end{tabular}

impact of high MIC's on clinical outcomes is not yet clear and further research is required to elucidate the impact of the latter. Furthermore, a large number of patients cannot use rifampin over extended durations due to adverse gastrointestinal reactions. In order to ensure effective treatment, our hospital started using rifamycin sodium as a replacement for rifampin from 2000. At present, rifamycin sodium drug sensitivity test strips are not available on the market. Thus, this study did not investigate bacterial susceptibility with respect to rifamycin sodium. In a separate retrospective cohort study, a combination of doxycycline and streptomycin was found to be the preferred regimen followed by co-administration of doxycycline and rifampin; no relapse or therapeutic failures were detected following these regimens [23]. However, because rifampin can enhance the plasma clearance of doxycycline resulting in lower doxycycline levels [24], we suggest that alternative medicines or combinations of antibiotics should be adopted to improve curative effects and reduce patient discomfort.

Mutations conferring rifampin resistance are confined almost exclusively to the $r p o B$ gene in most organisms. These mutations result in a decreased affinity of the DNA-dependent RNA polymerase to rifampin. However, alternative mechanisms of rifampin resistance have also been reported [25]. We did not observe any mutations in the rpoB gene of isolates that exhibited high MIC's or isolates that were resistant to rifampin. A previous study reported more than 100 rifampin resistant $B$. melitensis isolates in Qatar. However, $r p o B$ gene sequencing, results revealed that no $r p o B$ mutations were found among those isolates [26]. Moreover, because both brucellosis and tuberculosis are endemic in the analyzed region and rifampin is a first-line anti-tuberculosis agent, widespread use of rifampin has most likely resulted in higher MIC's pertaining to this antibiotic agent. Accordingly, we suggest that rifamycin sodium should be considered as a viable alternative for brucellosis treatment in regions exhibiting higher rates of rifampin-resistance. This study confirmed that $r p o B$ gene mutations were not present in the isolates that were resistant to rifampin. However, the previous study confirmed that $r p o B$ gene mutations were not the only mechanisms underpinning Brucella resistance to rifampin. Indeed, the excitation of several metabolic processes can also contribute to rifampin resistance in Brucella [27]. Furthermore, Brucella spp. share similar genomes and harbor two circular chromosomes that contain a number of putative drug efflux transporters [28, 29]. Consequently, efflux transporters may be involved in rifampin-resistance mechanisms in Brucella.

Cotrimoxazole is an alternative antimicrobial agent that has been recommended for the treatment of brucellosis in pregnant females and children. However, the development of resistance to cotrimoxazole in $B$. melitensis has become an important issue. In the present study, six isolates were resistant to cotrimoxazole. This finding is in agreement with previous studies [11, 19]. Moreover, Irajian et al. also reported that two Brucella strains were completely resistant to cotrimoxazole and one isolates exhibited intermediate resistance to it [30]. Sulfonamide resistance in most Gram-negative species involves the acquisition of an additional deoxyhypusine synthase (DHPS) gene on either a plasmid or a transposable element. The latter gene encodes for an enzyme that is not inhibited by sulfonamide and therefore bypasses inhibition of the chromosomally-encoded enzyme [31, 32]. Whole genome sequencing of drug-resistant strains is required to elucidate the mechanisms that underlie cotrimoxazole resistance. Furthermore, continuous surveillance programs should be implemented in hospital and clinical settings to better control and treat brucellosis in pregnant females and children.

A previous study reported that sparfloxacin, a new generation fluoroquinolone, exhibits excellent activity against Brucella. In our study, this drug exhibited excellent antimicrobial activity against all of the species analyzed. Minocycline, a second generation broad-spectrum antibiotic, displayed the strongest antibacterial activity and has a relatively long half-life, with plasma concentrations that were two to four times greater than those for other drugs [33]. Furthermore, this antibiotic has the greatest central nervous system (CNS) penetrance when compared with other tetracyclines, and the lipophilicity of minocycline appears to facilitate a high degree of intestinal absorption and tissue penetration [34]. We suggest that sparfloxacin and minocycline can be used as first-line antibiotics for the treatment of relapses and complications pertaining to patients with brucellosis. However, further studies are required to determine the role of these two antibiotics in the treatment of brucellosis. 
Among the 85 B. melitensis patients that were analyzed as part of this study, 50 patients received oral drug therapy (rifapentine and tetracycline: 6 weeks) and 35 cases required hospitalization (intravenous injection of rifamycin sodium, levofloxacin and cefoperazone sulbactam: 2 weeks) following diagnosis with Brucella infections. Following administration of medication for a further two weeks, nearly all of the patients improved to different degrees. Approximately six months later, one of the previously hospitalized patients was re-admitted to the hospital. Following an interview with this patient, it transpired that after treatment the patient continued to engage in sheep farming. Thus, it was suspected that the latter individual suffered a relapse. To determine the prevalence of relapse occurrence following the associated treatment regimen, a greater number of cases need to be analyzed. Another isolate from a different patient (a student) showed resistance to rifampin. The clinical manifestations (lumbago and joint pain) of this patient were relieved following the administration of rifapentine and tetracycline for 6 weeks. However, eight months after drug withdrawal, lumbago symptoms began to reoccur. This demonstrated that the patient was not completely cured and a timely review of the treatment regimen was required.

\section{Conclusions}

In summary, most of the antibacterial agents tested in our study demonstrated activity against Brucella melitensis and could be used in therapeutic regimens to combat associated infections. The exceptions were rifampin and cotrimoxazole. However, the intracellular localization of Brucella within monocytes and macrophages (of the reticulo-endothelial system) limits the choice of antimicrobial agents that can be used for the effective treatment of systemic and localized brucellosis. Although a variety of antimicrobial agents appear to be active in vitro, the results of susceptibility testing do not always correlate with clinical efficacy [35]. Thus, the specific conditions pertaining to each patient and the experience of the clinicians often determine which antibiotics are selected for treatment. However, in vitro sensitivity data raise the possibility of monitoring resistance in the future. Regular monitoring of drug sensitivity in Brucella is essential, and antibiotic administration and use should be rationalized to prevent future drug resistance.

\section{Abbreviations}

CLSI: Clinical and Laboratory Standards Institute; CNS: central nervous system; DHPS: deoxyhypusine synthase; MIC: Minimal Inhibitory Concentration; rpoB: RNA polymerase, beta subunit

\section{Funding}

This study was supported by the Medical and Hygiene Research Projects of the Inner Mongolia Health and Family Planning Commission (NO. 201301094) and the National Natural Science Foundation of China (NO. 81271900). The funders contributed to the study design and data collection.

\section{Availability of data and materials}

All data generated or analyzed during this study are included in this published article.

\section{Ethical approval and consent to participate}

This research was carried out according to the principles of the Declaration of Helsinki and was approved by the Ethics Committees of the National Institute for Communicable Disease Control and Prevention and the Chinese Center for Disease Control and Prevention (NO: ICDC-2014005). Informed consent was obtained from all of the patients prior to diagnosis. Brucella spp. were isolated from patients' blood samples following confirmation of their consent. No animal work was carried out as part of this study.

\section{Authors' contributions}

ZL performed the majority of the antimicrobial susceptibility tests, coordinated all work related to the study, performed data analysis, drafted the manuscript and participated in the design of the study; DD, MW and ZZ performed $r p o B$ PCR and participated in data analysis; YH, YD, HZ and DP participated in the design of the study and critically reviewed the manuscript. RL, HJ, BC and XX participated in the design of the study and managed the project. All of the authors read and approved the final manuscript.

\section{Consent for publication}

Not applicable.

\section{Competing interests}

The authors declare that they have no competing interests.

\section{Publisher's Note}

Springer Nature remains neutral with regard to jurisdictional claims in published maps and institutional affiliations.

\section{Author details}

${ }^{1}$ College of Veterinary Medical Inner Mongolia Agriculture University, Hohhot 010018, China. 'Ulanqab Centre for Endemic Disease Prevention and Control, Health and Family Planning Commission of Ulanqab, Ulanqab west Road, Jining 012000 Inner, Mongolia. ${ }^{3}$ Laboratory of Zoonoses, China Animal Health and Epidemiology Center, MOA, Qingdao, China. ${ }^{4}$ State Key Laboratory for Infectious Disease Prevention and Control, National Institute for Communicable Disease Control and Prevention/Collaborative Innovation Center for Diagnosis and Treatment of Infectious Disease, Chinese Center for Disease Control and Prevention, 155 Changbai Road, Changping, Beijing 102206, People's Republic of China. ${ }^{5}$ Institute of Military Veterinary AMMS, Changchun 130062, China

Received: 11 January 2017 Accepted: 4 January 2018

Published online: 16 January 2018

\section{References}

1. Pappas G, Papadimitriou P, Akritidis N, Christou L, Tsianos EV. The new global map of human brucellosis. Lancet Infect Dis. 2006;6(2):91-9. doi:10.1016/S1473-3099(06)70382-6.

2. Bayram Y, Korkoca H, Aypak C, Parlak M, Cikman A, Kilic S, Berktas M. Antimicrobial susceptibilities of Brucella isolates from various clinical specimens. Int J Med Sci. 2011;8(3):198-202.

3. Garcia-Rodriguez JA, Garcia SJ, Trujillano I. Lack of effective bactericidal activity of new quinolones against Brucella spp. Antimicrob Agents Chemother. 1991;35(4):756-9.

4. Jiang H, Fan M, Chen J, Mi J, Yu R, Zhao H, Piao D, Ke C, Deng X, Tian G, et al. MLVA genotyping of Chinese human Brucella melitensis biovar 1, 2 and 3 isolates. BMC Microbiol. 2011;11:256. doi:10.1186/1471-2180-11-256.

5. Tien N, Sung YJ, Chang YC, You BJ, Liang M, Lim YP, Ho WY, Lin HS, Ho MW, Ho CM, et al. The medical diagnostic approaches with phylogenetic 
analysis for rare Brucella spp. diagnosis in Taiwan. Biomedicine (Taipei). 2015;5(2):9. doi:10.7603/s40681-015-0009-6.

6. Wang Y, Zhang W, Ke Y, Zhen Q, Yuan X, Zou W, Li S, Sun Y, Wang Z, Wang $D$, et al. Human brucellosis, a heterogeneously distributed, delayed, and misdiagnosed disease in china. Clin Infect Dis. 2013;56(5):750-1. doi:10.1093/cid/cis980

7. Parlak M, Guducuoglu H, Bayram Y, Cikman A, Aypak C, Kilic S, Berktas M. Identification and determination of antibiotic susceptibilities of Brucella strains isolated from patients in van, Turkey by conventional and molecular methods. Int J Med Sci. 2013;10(10):1406-11. doi:10.7150/ijms.6565.

8. Baykam N, Esener H, Ergonul O, Eren S, Celikbas AK, Dokuzoguz B. In vitro antimicrobial susceptibility of Brucella species. Int J Antimicrob Agents. 2004;23(4):405-7. doi:10.1016/j.jiantimicag.2003.09.024.

9. Sayan M, Kilic S, Uyanik MH. Epidemiological survey of rifampicin resistance in clinic isolates of Brucella melitensis obtained from all regions of Turkey. J Infect Chemother. 2012;18(1):41-6. doi:10.1007/s10156-011-0281-7.

10. Barbosa PR, Reinato SA, Pinto DSMJ, Seles DE, Alves TM, de Sousa MSM, Minharro S, Heinemann MB, Lage AP. Reduced susceptibility to rifampicin and resistance to multiple antimicrobial agents among Brucella abortus isolates from cattle in Brazil. PLoS One. 2015;10(7):e132532. doi:10.1371/journal.pone.0132532.

11. Kinsara A, Al-Mowallad A, Osoba AO. Increasing resistance of Brucellae to co-trimoxazole. Antimicrob Agents Chemother. 1999;43(6):1531.

12. Olitzky AL. Laboratory techniques in brucellosis. Harefuah. 1976;91(11):408-9.

13. Bricker BJ, Halling SM. Differentiation of Brucella abortus bv. 1, 2, and 4, Brucella melitensis, Brucella ovis, and Brucella suis bv. 1 by PCR. J Clin Microbiol. 1994;32(11):2660-6.

14. CLSI. Methods of antimicrobial dilution and disk susceptibility testing of infrequently isolated or fastidious bacteria. Approved guidelines- second edition. CLSI document M45-A2. Clinical and Laboratory Standard Institute: Wayne; 2010.

15. CLSI. Performance standard for antimicrobial susceptibility testing: twentyfourth informational supplement. CLSI document M100-S24. Clinical and Laboratory Standard Institute: Wayne; 2014.

16. Marianelli C, Ciuchini F, Tarantino M, Pasquali P, Adone R. Genetic bases of the rifampin resistance phenotype in Brucella spp. J Clin Microbiol. 2004; 42(12):5439-43. doi:10.1128/JCM.42.12.5439-5443.2004.

17. Valdezate S, Navarro A, Medina-Pascual MJ, Carrasco G, Saéz-Nieto JA. Molecular screening for rifampicin and fluoroquinolone resistance in a clinical population of Brucella melitensis. J Antimicrob Chemoth. 2009;65(1):51-3.

18. Abdel-Maksoud M, House B, Wasfy M, Abdel-Rahman B, Pimentel G, Roushdy G, Dueger E. In vitro antibiotic susceptibility testing of Brucella isolates from Egypt between 1999 and 2007 and evidence of probable rifampin resistance. Ann Clin Microbiol Antimicrob. 2012;11:24. doi:10.1186/1476-0711-11-24.

19. Lopez-Merino A, Contreras-Rodriguez A, Migranas-Ortiz R, Orrantia-Gradin R, Hernandez-Oliva GM, Gutierrez-Rubio AT, Cardenosa O. Susceptibility of Mexican brucella isolates to moxifloxacin, ciprofloxacin and other antimicrobials used in the treatment of human brucellosis. Scand J Infect Dis. 2004;36(9):636-8. doi:10.1080/00365540410020767.

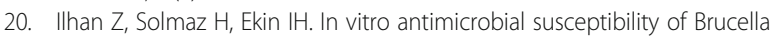
melitensis isolates from sheep in an area endemic for human brucellosis in Turkey. J Vet Med Sci. 2013;75(8):1035-40.

21. Gattringer KB, Suchomel M, Eder M, Lassnigg AM, Graninger W, Presterl E. Time-dependent effects of rifampicin on staphylococcal biofilms. Int J Artif Organs. 2010;33(9):621-6.

22. Hashim R, Ahmad N, Mohamed ZJ, Tay BY, Mohd NA, Zainal S, Hamzah H, Hamzah SH, Chow TS, Wong PS, et al. Identification and in vitro antimicrobial susceptibility of Brucella species isolated from human brucellosis. Int J Microbiol. 2014; 2014(596245. doi:10.1155/2014/596245.

23. Rahil Al, Othman M, Ibrahim W, Mohamed MY. Brucellosis in Qatar: a retrospective cohort study. Qatar Med J. 2014;2014(1):25-30. doi:10.5339/qmj.2014.4.

24. Colmenero JD, Fernandez-Gallardo LC, Agundez JA, Sedeno J, Benitez J, Valverde E. Possible implications of doxycycline-rifampin interaction for treatment of brucellosis. Antimicrob Agents Chemother. 1994;38(12):2798-802.

25. Goldstein BP. Resistance to rifampicin: A review. J Antibiot. 2014;67(9):625-30.
26. Deshmukh A, Hagen F, Sharabasi OA, Abraham M, Wilson G, Doiphode S, Maslamani MA, Meis JF. In vitro antimicrobial susceptibility testing of human Brucella melitensis isolates from Qatar between 2014 - 2015. BMC Microbiol. 2015;15(1) doi:10.1186/s12866-015-0458-9.

27. Sandalakis V, Psaroulaki A, De Bock P, Christidou A, Gevaert K, Tsiotis G, Tselentis Y. Investigation of rifampicin resistance mechanisms in Brucella abortus using MS-driven comparative proteomics. J Proteome Res. 2012;11(4):2374-85. doi:10.1021/pr201122w.

28. Traxler RM, Lehman MW, Bosserman EA, Guerra MA, Smith TL. A literature review of laboratory-acquired brucellosis. J Clin Microbiol. 2013;51(9):3055-62. doi:10.1128/JCM.00135-13.

29. Paulsen IT, Seshadri R, Nelson KE, Eisen JA, Heidelberg JF, Read TD, Dodson RJ, Umayam L, Brinkac LM, Beanan MJ, et al. The Brucella suis genome reveals fundamental similarities between animal and plant pathogens and symbionts. Proc Natl Acad Sci U S A. 2002;99(20):13148-53. doi:10.1073/pnas.192319099.

30. Irajian GR, Masjedian JF, Mirnejad R, Piranfar V, Zahraei ST, Amir MN Ghaznavi-Rad E, Khormali M, Species-specific PCR. For the diagnosis and determination of antibiotic susceptibilities of Brucella strains isolated from Tehran, Iran. Iran J Pathol. 2016;11(3):238-47.

31. Arabi H, Pakzad I, Nasrollahi A, Hosainzadegan H, Azizi JF, Taherikalani M, Samadi N, Monadi SA. Sulfonamide resistance genes (sul) M in extended Spectrum Beta lactamase (ESBL) and non-ESBL producing Escherichia Coli isolated from Iranian hospitals. Jundishapur J Microbiol. 2015;8(7):e19961. doi:10.5812/jjm.19961v2.

32. Huovinen P, Sundström L, Swedberg G, Sköld O. Trimethoprim and sulfonamide resistance. Antimicrobial Agents \& Chemotherapy. 1995;39(2):279-89.

33. Agwuh KN, MacGowan A. Pharmacokinetics and pharmacodynamics of the tetracyclines including glycylcyclines. J Antimicrob Chemother. 2006;58(2):256-65. doi:10.1093/jac/dkl224.

34. Barza M, Brown RB, Shanks C, Gamble C, Weinstein L. Relation between lipophilicity and pharmacological behavior of minocycline, doxycycline, tetracycline, and oxytetracycline in dogs. Antimicrob Agents Chemother. 1975;8(6):713-20.

35. Hanson GW. Brucellosis in humans and animals. Ceylon Med J. 2009:52(2):66.

\section{Submit your next manuscript to BioMed Central and we will help you at every step:}

- We accept pre-submission inquiries

- Our selector tool helps you to find the most relevant journal

- We provide round the clock customer support

- Convenient online submission

- Thorough peer review

- Inclusion in PubMed and all major indexing services

- Maximum visibility for your research

Submit your manuscript at www.biomedcentral.com/submit 